\title{
SPIRIT THAT WANTS TO FLY - ADORNO UNDER A SPELL
}

- ABSTRACT: The starting point of Demirovic's text is Adorno's idea that concepts as forms of thinking are constellations of power. Differently from many interpretations of Adorno as resigned, Demirovic shows that this assumption enables Adorno to give his own theory the character of interventions in the ideological consensus of everyday life with regard to emancipation.

- KEYWORDS: constellation; dialectics; freedom; enlightenment; emancipation.

Adorno's name is associated with social theory and criticism becoming a cultural event in their own right. Over the years he has frequently been honored as a figure from recent German intellectual history. His name designates a small square near the university in Frankfurt; an Intercity express train on one of the less important routes is named after him; the city of Frankfurt awards an Adorno Prize; and there are the Adorno Lectures, organized jointly by the Institut für Sozialforschung (Institute for social research) and the Suhrkamp publishing house. At first glance, this may seem surprising, since Adorno's theory not only represents a fundamental critique of modern bourgeois society but maintains an emphatically distanced and skeptical attitude to the activities of (the) culture (industry). Not least for that reason, it became an important reference point for the protest movements of the 1960s. There was also criticism, however. Some said-more out of frustration-

1 Lecturer at Frankfurt University and former researcher at Institut für Sozialforschung. 
that ultimately Adorno too was co-opted; others, cruelly and sometimes maliciously, considered the theory a dubious intellectual model that radically negated contemporary culture and yet did not hesitate to enjoy the privileges it offered. With greater perspective, it is evident that Adorno's theory met with great public approval very early on. By "early" I mean after his return from exile in the United States in 1949. In the eyes of his contemporaries Adorno was a philosopher on the level of Heidegger; his theory was understood in grand words to be an epochal contribution to philosophy and a contemporary continuation of Marx's theory (Demirovic, 1999, p.525ss). That is rather astonishing as Adorno's books relate to Marx's theory so indirectly. Adorno quickly became known as a sociologist of music for his books on the philosophy of modern music and on Richard Wagner - that is, for books that corresponded to a reputation that had preceded his return: as Thomas Mann's competent partner in conversation during the writing of Doctor Faustus. Adorno's book Against Epistemology was rather unwieldy, and it probably found even fewer readers than Dialectic of Enlightenment, whose first printing could still be found in bookstores in the late 1950s. The two books of cultural criticism, Minima Moralia and Prisms, enjoyed a lively and generally positive reception, for all the criticism. Other essays on music, literature, and sociology as well as numerous public lectures and discussions surely contributed to his being awarded the literary prize of the Verband deutscher Kritiker (Association of German critics) for his complete oeuvre in 1958-59, just a few years after his return.

Adorno was frequently criticized; there were numerous intrigues against him, against what he represented, and against the Institut für Sozialforschung; nevertheless, "from the beginning" his theory also met with goodwill and enthusiasm. Adorno was well aware of the polarizing effect of this theoretical praxis and saw its positive consequences. In a discussion at the sociologists' convention in 1968 he defended himself against Dahrendorf's reproach that his theory was impractical and his own language had taken on the character of a jargon. He countered both objections with the argument that Dahrendorf was ignoring the critical and parodic aspect of the expression "jargon" and underestimating the practical aspect of ideological critique. Adorno preferred to think that he had

contributed a little toward making the German atmosphere less ideological. Socalled jargon of the sort my closest friends and I are accused of - if its distinguishing feature is to be that it eludes easy understanding - comes about pre- cisely because it is an attempt to express the matter very rigorously in order to avoid the sloppiness of the universal communication that, given the nature of society today, itself only serves to obscure the truth by offering an illusion of universal understanding (Adorno, 1972a, p.581).

This comment on the discussion reveals how Adomo conceived his theoretical work, which resists the illusion of consensus. Clearly, Adorno was not pursuing the goal of contributing to a linear and compact form of social theory that first revealed its standards in its basic philosophical grounds, then went on to build up neatly from these fundamental assumptions, and finally ventured on to reflect on diagnoses of its day. Rather, he conceived it as a theory that developed its truth claim solely in material analyses of concepts and of the experiences linked with these concepts. Hence it was not a theory arising out of the depths of a universalism grounded in anthropology but a theory that emerged through its "interventions" into specific contexts - in a series of reflections on concepts, keywords, and terms by means of which the theory itself repeatedly entered into a polemical relationship toward quotidian understanding and to ideology and contributed to the responsibility of the individual (Adorno, 1998a, p.278). ${ }^{2}$ Truth is not brought to bear when it ultimately lays claim to and promulgates for its own theory an argumentation that is carried through according to the rules of the scientific discipline but rather when experiences and impulses are developed terminologically and brought together into concrete theoretical constellations. Theoretical work is what brings the concepts together into constellations. In such constellations it becomes possible to tell how the concepts have enriched new experiences and meanings historically. The insight that this produced into how the meaning of concepts is shifted, extended, and restricted is tantamount to an understanding of the state of development of bourgeois society, since this state is always either mediated in concepts or concerned to block such mediation by means of naturalization - and that in turn points to a particular conceptually mediated state of society. For Adorno, the ever new production of such conceptual constellations in and through such texts represents an emancipatory practice of theory. The concepts seek and summon one another. Someday a constellation could form in which the reconciling word is spoken, the word that catches fire in the conceptual

2 Hereafter cited in the text as MTP 
context in such a way that relationships among individuals are revealed to them. That which seems to be under the spell of the natural laws of society will then become recognizable to them as practices they produce and hence subject to change. According to Adorno, society has long since reproduced itself as a natural context entirely on the basis of traditional power relations; freedom has long since been objectively possible on the basis of the state of social cooperation - freedom as the overcoming of the tribulation of labor and the necessity of material laws. Only a lack of insight stands in the way. What seems so tiny, however, is immense, because the disposition to reason, to theoretical insight and experience, is threatened even in this social development by the processes that produce "semiculture" [Halbbildung], that prevent one from elevating oneself above the extant, the positive. "In a climate of semiculture, the facts of education that have reified in commodities survive at the expense of their truth content and their living connection to living subjects" (Adorno, 1972b, p.103). ${ }^{3}$ The frozen force field of concepts must made to oscillate again if this regression is to be overcome. Like truth, theory must establish the truth capabilities of the individual; a politics of truth is necessary to see to it that theory itself remains (or becomes again) a binding orientation for action. ${ }^{4}$ In that respect Adorno is not pessimistic at all. Rather, his theoretical practice represents the attempt to produce constellations in which the concepts can assemble in such a way that, once the reconciling word is spoken, the conceptual experience that makes emancipation possible will be achieved.

This kind of work on conceptual constellations reflects back on the theory, since the latter is shifted with each constellation and thereby postponed. Theory is found neither in a "first" text nor in a "last" text; it is directed just as much against the expectation of a linear system as against the notion that theory is an idea that guards over a constitutive subject autonomously, so to speak, and that could be grasped by a onetime hermeneutical action on the part of the interpreter - that could perhaps be grasped even better by this symbolic act of violence than would be possible for the author, as if the interpreter could somehow escape the logic of discourse and context. Adorno viewed his theory as itself a process, as a series of interventions.

3 Hereafter cited in the text as 'TH.

4 For greater detail on Adorno's politics of truth, see Demirovic, Der nonkonformistische Intellektuelle.
The call for binding statements without a system is a call for thought models, and these are not merely monadological in kind. A model covers the specific, and more than the specific, without letting it evaporate in its more general, generic concept. Philosophical thinking is the same as thinking in models; negative dialectics is an ensemble of analyses of models (Adorno, 1983, p.29). ${ }^{5}$

Theory has no zero point; it is its own form of praxis. The truth has a temporal kernel [Zeitkern]; theory does not settle on the concept in a single text; rather, every text feeds the expectation that in the next text the constellation could occur that call theory, concept, and experience together into the reconciling word. But Adorno gives a practical turn to this desire for a theory that will somebody succeed. "If thinking bears on anything of importance, then it initiates a practical impulse, no matter how hidden that impulse may remain to thinking. Those alone think who do not passively accept the already given" (MTP 264). The desire for truth and theory is sưpposed to ignite the desire for the state of affairs that will someday come about in which people can live peacefully together without hunger, without the tribulation of labor. Nevertheless, despite this insistence that reason must be realized objectively-that is, out there-theory for Adorno is still what represents a free form of socialization: "Theory speaks for what is not narrow-minded. Despite all of its unfreedom, theory is the guarantor of freedom in the midst of unfreedom" (MTP 263). Theory is the benign and tender. "Reality's spell over spirit prevents spirit from doing what its own concept wants to do when faced with the merely existent: to fly" (Adorno, 1998b, p.157). ${ }^{6}$ The freedom of spirit and of culture stands for the goals that can only be achieved through praxis and that are the binding standard for praxis it self. Understood correctly, the real goal would ultimately be its own abolition (MTP 267): the overcoming of the contradictions of theory and practice, the separation of intellectual and physical labor.

Like everyday understanding, theory becomes ideology when it makes itself the advocate of the objectively existing and calls for reason-for a form of reason that compels us to accommodate ourselves to the conditions and tendencies of society.

In the hypostasis of spirit through culture, reflection transfigures the separation of physical and intellectual labor that society urges upon us. The old injustice is justified as the objective superiority of the dominant principle, where-

5 Translation modified; hereafter cited in the text as ND. 6 Hereafter cited in the text as $P$. 
as it is of course only by virtue of being separated from the dominated that it becomes possible to put an end to the stubborn repetition of power relations. Accommodation, by contrast, is the immediate scheme of continuing domination (TH 96).

In Adorno's view, society is humankind's attempt to become free of the enslavement of nature. Through cooperation and intercourse with one another, humans develop skills that they did not possess when alone that enable them to overcome problems of self-preservation. This liberation from nature has always failed thus far, however; something enslaving and repressive clings to it, because it can only be achieved by dominating nature and accommodate ourselves to it. Although society perceives that nature is alien, it allows itself to be determined by nature's necessities when for the sake of self-preservation it compels individuals to integrate and accommodate themselves to the immutable imperative. Necessity and freedom, accommodation and autonomy, ideology and reason - all are mixed up an equally inseparable way just are camps of general and particular interests are. The general interest is that people live and survive; its particularist aspect is that it usually privileged and dominant groups that determine how the survival of all is to be achieved, so that the survival of many is either precariously ensured or not at all. Ideological critique is aimed at the insight that the powerful oppress people with a conception of rationality and theory, to the extent that their survival is supposed to be possible only if they allow themselves to be dominated. Reason and truth are themselves dialectical constellations, shot through with the contradictions and antitheses of society. In retrospect, the Enlightenment has proven to be naive and one-sided, because it thought to be enough to confront myth with reason without examining its own praxis, the praxis of reason; which compels individuals to responsibility on a new and higher level. Limited reason continues the dominance of nature into society: the accommodation to external nature-subjugating it and dominating it to exploit for the survival of the species - ultimately leads to social relations that are for their part effective a natural enslavement. "Every attempt to break the natural thralldom, because nature is broken, enters all the more deeply into that natural enslavement" (Adorno, Horkheimer, 1997, p.13). ${ }^{7}$ It is considered rational to acknowledge objective circumstanc-

\footnotetext{
7 Hereafter cited in the text as DE.
}

es, accommodate oneself to them, and to enforce them - simply because they exist. This is seen most dramatically, perhaps, in socially necessary labor. When society's need for it is so clearly declining, where the wealth of the society is so enormous, liberation from labor in the name of and with the promise of progress is postponed in favor of ever more work - known as "full employment" - in order to avoid it altogether.

Adorno explicitly conceives his theory as partisanship for preserving, spreading, and developing freedom and for "tendencies toward true humanism" (DE $\mathrm{x}$ ). This should not be considered trivial. Adorno refuses to have anything to do with the notion that the critic should also make practical proposals or picture what the state of reconciliation would look like. He does not simply consider such demands censorship of critical thinking. They would also constitute a limitation on the freedom of those who live in the future if those who live in the present were to prescribe the future; it also shows a lack of responsibility for the present and a lack of autonomy if individuals acting today appeal to some coming future for which they claim authority and whose laws they believe they enforce. Appealing to historical necessities and societal regularities [gesellschaftliche GesetzmäBigkeiten] is a sign of an authoritarian character. It is necessary to know that it could be otherwise. But it must be developed conceptually and in terms of the concrete object; it cannot be postulated from outside as an abstract opposition, because then it would be harmless and nonbinding. Nothing beyond determinate negation is possible if emancipation is not to become an authoritarian principle. This is also an appeal for reforms. "At a historical moment, however, where a praxis that would refer to the totality appears to be blocked everywhere, even paltry reforms may presume more right than they in fact are due" (Adomo, 1998c, p.4). Even the smallest improvements can achieve the good. To put it paradoxically, one of these small reforms is ultimately the transformation of the whole itself. If we are to be able to act in complete freedom, such a radical transformation cannot be an abstract historical principle; rather, it must be the completely mediated, a concrete meaning that reveals itself to the actors as a sensible orientation in their everyday praxis: "Enlightenment is realized and reaches its term [hebt sich auf] when the nearest practical ends reveal themselves as the most distant goal now attained" (DE 42). Despite this general abstention from more concrete proposals and projects for emancipation, Adorno clearly reveals his partisanship; and it repeatedly leads him to make the case that humanity should finally realize its own concept. He does not, however, understand "humanity" 
as a generic concept; neither is it a necessity of the species that takes precedence over the individual in the sense of an absolute imperative for survival. Humanity is the form that freedom takes-namely, an association of free and separate individuals; an association in which individuals no longer have to live according to principles of abstract, general economic regularities [Gesetzmäßigkeiten] or moral, legal norms but can instead develop the diversity and plurality of varied individuals and of their potentialities. Realizing humanity means the sublation and overcoming of humanity as a mere "species existence" - that is, a form of existence in which all that matters is the survival of the collective, while individuals are sacrificed. Nevertheless, however much Adorno may place the individual at the center of his reflections, it is not a matter of a liberal abandonment of the general in favor of the individual. The dialectic of general and individual must be endured and dealt with - it was and would be another false reconciliation if the solution were found in the privileging of one side. Hence the individual cannot be the solution, because the individual is itself, down to its most delicate reactions, a product of power. "In a state of freedom even the sharpest critic would be a different person, like the ones he wants to change" (ND 352). But extreme individuation is the placeholder of humanity. The individual can be avant-garde as an individual - not in the elite sense but in the free sense. Individuals lead the way; they open up and break a path that will then be open to all. "Humanity can be thought only through this extreme form of differentiation, individuation, not as a comprehensive generic concept" (P 151).

Ingrained routines in the way authors and theories are received can frequently obstruct access to them. This applies to Adorno as well. Some claim, in the name of a critical social theory in need of revitalization, that his theory is acquiescent, unproductive, up-to-date with a democratic society; others give the impression that time stood still after Adorno and that there were not frequent social conflicts. Precisely in light of such conflicts and camps representing interests, however, Adomo's reflections need to be acquired anew. Even criticizing them would often help us to see their relevance. In conclusion, I will address a theorem that is as productive as it is problematic.

The concept of dialectic has frequently been criticized for its teleological nature: it coerces diversity into the logic of contradictions that struggle of their own accord for sublation. Adorno himself made this criticism; it is the central motif of his conception of negative dialectics (ND 5). But he also appropriated this teleology and even made use of a sort of judo thinking that Hegel himself had adopted. The direction of his argument is that bourgeois thought from Descartes by way of Spinoza and on, finally, to Hegel pressed for a system, a paradoxical form of thought that forces together history and rational construction with ahistoricity, systemic conclusion, and pure validity, just as if in the system, by means of immanent self-movement, history and the present could settle on a concept that no longer acknowledges anything beyond. By means of a concept that is self-contained in its immanence, Adorno wanted to get beyond this horizon. Anything but acquiescent, the radicalness of his thought lay in the desire to force all, literally all, of the material details of concrete life into this teleology of a self-contained system, not in order to be lugubriously and despairingly content with it but to conceive a completely new kind of friend. If everything were a system, transformation and true progress would be possible. At the same time, only in this way could freedom be possible on the highest level of historical and social natural growth hitherto. Then, even if only tiny residues of natural growth remained uncomprehended by the system, even if only trace elements of the falsely reconciled remained outside the walls of the system, then it would be possible, as happened with the known attempts at socialism, then these residues could bring themselves to bear as nontransparent forms of natural domination and thereby sabotage the process of further enlightenment and emancipation. Then, even in the realm of freedom, unacknowledged unfreedom would continue to exist. For that reason, Adorno's effort was focused on proving that everything was subsumed to the system or at least tended to that. Many times he stated his intention to realize a proof materially on the object. Nevertheless, this work never got beyond preparatory arguments and methodological reflections. It remains a productive challenge, however, since in principle it remains true that emancipation and the production of other, free living conditions that are no longer terrorized by the natural laws of society, in particularly the economy, can only be brought about responsibly where the extant highest level of freedom is perceived as insufficient. Admittedly, the question does arise whether Adorno's intention could be pursued today, since his gesture of condensing everything into one concept of negative totality cannot be repeated. That would indeed lead to the acquiescence that many attributed to Adorno. Nevertheless, Adorno's theory contributed to the liberation of the emancipatory impulse to live a life of diversity and difference. Many different forms of life have struggled for their rights and freedom. They are not themselves the true form of freedom - often they 
are exploited on the new level again, and they contribute to a continued reproduction of power relations. The system in its one-dimensionality imposes itself again; today, when no one -not even among the systems theorists - wants to think of the system qua system, and with the neoliberal revolution as overarching consensus, it is thought there is no alternative. But the basis for critique and social theory has for some time lain not only in this teleology of the system but also in the fact that emancipatory efforts exist everywhere that make good on claims on variety and happiness, on life without fear, hunger, or tribulation. Emancipatory thought has long since been moving within a dialectic of the system that is constantly trying to totalize itself anew but constantly fails, owing to the continued existence of class divisions - and only reproduces itself in this movement. This dialectic had already emerged in Adorno's work, although he would not have explained this movement itself in terms of a material social theory, as he was too concerned with standing up for theory and truth as a binding practice for theory. For that reason, Adorno is very timely in an untimely way. Hardly anyone in the tradition of emancipatory thought, which was always concerned with equality, thought through this dialectic of identity and nonidentity as thoroughly as Adorno did, or elevated nonidentity to the standard for emancipation. At the same time, however, his theory always reminds us that nonidentity is not the final standard. For as along as the contradictions between the system and nonidentity continue to surface, as long as this alternative and its dialectic continue to claim validity, social relations will always be subject to the logical of natural domination and remain unfree.

\section{Translated from the German by Steven Lindberg}

DEMIROVIC, A. O espírito que quer voar - Adorno encantado. Trans/Form/ Ação, (São Paulo), v.27 (1), p.27-37, 2004.

- RESUMO: O ponto de partida do presente artigo é a idéia adorniana de que os conceitos como formas de pensamento são constelações de poder. Diferentemente de muitas interpretações que vêem em Adorno um resignado, Demirovic mostra que essa idéia permite que o filósofo dê à sua própria teoria o caráter de intervenção no consenso ideológico da vida quotidiana no tocante à emancipação.

- PALAVRAS-CHAVE: constelação; dialética; liberdade; esclarecimento; emancipação.

ADORNO, Th. W. (1968): “Diskussionsbeitrag zu 'Spätkapitalismus oder Industriegesellschaft?'". In: __. Gesammelte Schriften. Frankfurt am Main: Suhrkamp, 1972a. v.8.

- "Marginalia to Theory and Praxis". In idem. Critical Models: Interventions and Catchwords. Trans. Henry W. Pickford. New York: Columbia Univ. Press, 1998a.

. "Theorie der Halbbildung". In: am Main: Suhrkamp, 1972b. 1983.

. "Progress". In: _. Critical Models: Interventions and Catchwords. Trans. Henry W. Pickford. New York: Columbia Univ. Press, 1998b.

. Critical Models: Interventions and Catchwords. Trans. Henry W. Pickford. New York: Columbia Univ. Press, 1998c.

ADORNO, Th. W., HORKHEIMER, M. Dialectic of Enlightenment. Trans. John Cumming. London and New York: Verso, 1997.

DEMIROVIC, A. Der nonkonformistische Intellektuelle: Die Entwicklung der Kritischen Theorie zur Frankfurter Schule. Frankfurt am Main: Suhrkamp, 1999. 